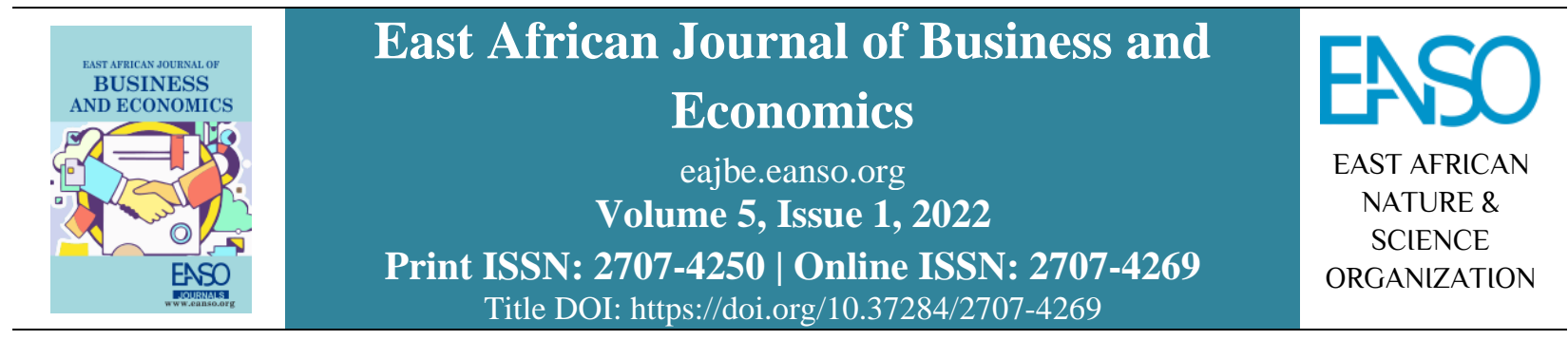

Original Article

\title{
The Relationship between Gender Diversity and Employee Performance in the County Government of Bomet, Kenya.
}

\author{
Gillian Chepkemoi ${ }^{1 *}$, Dr. Williter Rop, $\mathrm{PhD}^{1} \&$ Dr. Patricia Chepkwony, PhD ${ }^{1}$ \\ ${ }^{1}$ University of Kabianga. P. O. Box 2030-20200, Kericho, Kenya. \\ * Author for Correspondence ORCID: https://orcid.org/0000-0001-5259-8639; Email: gillian.chepkemoi.gc@ gmail.com.
}

Article DOI: https://doi.org/10.37284/eajbe.5.1.564

\section{Date Published: ABSTRACT}

23 February 2022 Gender diversity is an essential aspect of both private and public organizations. The concept has continued to evolve because of the need to tap into different

Keywords: abilities possessed by different gender at the workplace. However, previous studies have not indicated to what extent workforce diversity is related to

Workforce Diversity,

Gender Diversity,

Employee employee performance in various organizations. On this basis, the paper sought to investigate the relationship between gender diversity and employee performance in the County Government of Bomet, Kenya. The paper was guided by social identity theory. The study adopted a correlational research design, and Performance. the target population was 3,320 employees working in various departments within the County Government of Bomet. Fisher's formula was used to determine the sample size for the study, which was 91. Data was collected using a structured questionnaire. The reliability of the research instrument was examined through the use of Cronbach's alpha coefficient, where an alpha coefficient of 0.850 was obtained. Content and construct validity of the instrument validity were ensured through extensive literature review and consultation with human resource management subject experts. Data analysis was done using correlation and regression analysis. Data were presented using frequency tables, means, and standard deviation. According to the study results, it was revealed gender diversity revealed a positive relationship ( $\mathrm{r}=0.689$; $\mathrm{p}<0.05)$ with employee performance. In general, gender diversity influenced employee performance by $72.3 \%(\mathrm{R} 2=0.723)$. According to the study findings, it was recommended that county governments ought to advocate for workforce diversity, explicitly focusing on gender diversity to increase employee performance.

\section{APA CITATION}

Chepkemoi, G., Rop W., \& Chepkwony, P. (2022). The Relationship between Gender Diversity and Employee Performance in the County Government of Bomet, Kenya. East African Journal of Business and Economics, 5(1), 90-98. https://doi.org/10.37284/eajbe.5.1.564.

90 This work is licensed under a Creative Commons Attribution 4.0 International License. 


\section{CHICAGO CITATION}

Chepkemoi, Gillian, Williter Rop \& Patricia Chepkwony. 2022. "The Relationship between Gender Diversity and Employee Performance in the County Government of Bomet, Kenya". East African Journal of Business and Economics 5 (1), $90-98$. https://doi.org/10.37284/eajbe.5.1.564.

\section{HARVARD CITATION}

Chepkemoi, V., Rop W. \& Chepkwony, P. (2022) "The Relationship between Gender Diversity and Employee Performance in the County Government of Bomet, Kenya", East African Journal of Business and Economics, 5(1), pp. 90-98. doi: 10.37284/eajbe.5.1.564.

\section{IEEE CITATION}

G. Chepkemoi, W. Rop \& P. Chepkwony, "The Relationship between Gender Diversity and Employee Performance in the County Government of Bomet, Kenya”, EAJBE, vol. 5, no. 1, pp. 90-98, Feb. 2022.

\section{MLA CITATION}

Chepkemoi, Gillian, Williter Rop and Patricia Chepkwony. "The Relationship between Gender Diversity and Employee Performance in the County Government of Bomet, Kenya”. East African Journal of Business and Economics, Vol. 5, no. 1, Feb. 2022, pp. 90-98, doi:10.37284/eajbe.5.1.564.

\section{INTRODUCTION}

Globalization has enabled many organizations to embrace the concept of diversity in their workplace. Diversity is the intentional employment of a workforce comprised of people with different characteristics such as race, sexual orientation, age, gender, ethnicity, religion, education, and other attributes (Farooqi, 2017). However, diversity in some workplaces has been a challenge. This has led to many countries adopting legislative laws, policies, bills of rights, and advocacy to ensure diversity in the workplace and that citizens have equal opportunities to access employment opportunities (Kunze, Boehm, \& Bruch 201).

According to Patten (2016), many countries in the west have embraced gender diversity and reemphasized its importance over time through the bill of rights (Wilden, Gudergan, Nielsen \& Lings, 2013). Gender diversity has also been used as a criterion to fight discrimination in the workplace. Western countries such as the United States of America have adopted legislations that ensure all organizations embrace gender diversity at their workplace to provide equal job opportunities for all.

In India, there are growing figures of progressive firms that value gender diversity in the workforce. According to Preeti, Poonama, and Ekanshi (2014), India's organizations with diverse workforces encourage increased productivity, intellectual and knowledge exchange, effective communication, diverse experience, and a learning rate. Gender diversity has been taken as social responsibility, economic payback, resource imperative, legal requirement, marketing, and capacity-building strategy (Iqbal \& Shah, 2015).

In Africa, the primary concern in the workplace environment is cultural and gender balance which has prompted the African nations to advocate for diversity to reduce cases of discrimination. There is still a challenge for most top management in most companies where one gender is domineering in top management. At the same time, the other is left to take lower management jobs, an act of discrimination that demoralizes employees hence leading to poor performance (Gacheri 2012). A study by Eshetu (2017) on the relationship between gender diversity and employee work performance in the case of Addis Credit and Savings Institution established a strong relationship between gender and employee performance. The study revealed that gender balance at the workplace indicated equality, which enhanced employee motivation, leading to enhanced efficiency.

Firms embracing gender diversity tend to compete favorably and place themselves in a better position in the global environment. An assessment of the impact of gender diversity on employee performance by Mwinami (2014) established that gender diversity had a positive influence on employee performance. However, the study also revealed that some organizations had challenges that affected them from reaping the best from diversity. Some of the challenges included: Lack of policy; Lack of human resource expertise; Lack of Management commitment; Lack of Common 
understanding, and the Tendency by some employees to think that one gender is better at work than the others. In conclusion, the study recommended that organizations improve management commitment, recruit expertise, and policy formulation on diversity management.

In Kenya, Gacheri (2012) and Elsaid (2012) researched the Kenya banking industry, examining the effect of workforce diversity on employee performance. The study findings indicated that gender diversity had an impact on employee performance. In this study, Gacheri found that gender diversity influenced managers and nonmanagers differently. Further, the study established that the effects of gender diversity at the management level influenced managers' performance rather than junior employees. Sabharwal (2014) argued that gender diversity within personnel management could be a source of competitive advantage and improvement of stakeholder' satisfaction.

Another study by Munjuri and Maina (2013) on diversity management in the banking industry in Kenya indicated that the industry had developed strategies that supported gender groups and advocated for equal chance and employment opportunities for all. The various tests of hypotheses from the study indicated a significant relationship between employee performance and productivity levels in the bank due to gender diversity.

\section{LITERATURE REVIEW}

This section presents the study's theories, the literature review, and the conceptual framework.

\section{Theoretical Review}

The study was anchored on Social Identity Theory.

\section{Social Identity Theory}

This theory was developed by Henri Tajfel and John Turner in the early 1970s and advanced by other scholars in the 1980s. The postulate suggests that individuals regroup into different social groups such as nationality, age, gender, and school. This theory indicates that individuals in groups or clusters with which they are associated because of similar characteristics tend to behave in a manner that affirms their identity to the group they are associated with.

This theory has been used by other researchers such as Anjiri (2018), who sought to determine the impact of workforce diversity on the information technology performance of companies in Nairobi County. The theory is supported by Kurtulus and Tomaskovic-Devey (2012), who argued that individuals identify them based on their affiliation or association to a given social group. They are most likely to change their character and take on different roles to be accepted into a given group. Hogg, Terry, and White (1995), concerning this theory, assert that individual identity and behavior develop among individuals concerning the social grouping they adapt to. Individuals are perceived to belong to a group when they have identical characteristics and attributes (Kulik \& Bainbridge, 2006). The theory of social identity can be a theory of people who belong to a similar group and portray identical characteristics and behavior (Hogg, 1995). It stresses how people perceive themselves and the groups they belong to.

The theory fits this study because of the group dynamism in organizations where employees reflect the same behavior. Group dynamism for group behavior is only determined in social interaction context where social categorization is based. The emergency of group dynamics plays a significant role in accelerating group formation. This theory seems to be accelerating the formation of groups simply because of its principles. However, the theories post some weaknesses; For instance, it only focuses on social recognition and individual processes, which is part of group dynamism.

Further, the theory best explains in-group favoritism than genuine inter-group hostility and out-group exemptions. The theory is relevant to this study as it depicts how employees relate, interact, and form groups of different ethnic groups. Therefore, the theory supported the study by examining the relationship between ethnic diversity and employee performance in the County Government of Bomet.

\section{Empirical Review}

Literature from past scholarly articles, publications, and other secondary data was reviewed to establish a research gap for the study. 


\section{Gender diversity and Employee Performance}

Gender is an examination and description of a person's characteristics that may either be found to be female or masculine (McDowell, 2018). Female and male attributes are all found in any workforce. Therefore, when embracing gender diversity, it is taken as an organization policy; it ensures that there has to be a balance between the two in the organization. Gender diversity strategy can be implemented in the organization during recruitment and job progression.

Positive gender diversity often enables an organization to achieve a competitive advantage over other organizations because it can attract both sexes and tap diverse skills and abilities, improving productivity. Conversely, gender diversity in the workplace may be detrimental to employees' performance due to psychological and physical differences between the genders. The perception that different roles can be carried out effectively by different genders in the workplace may demoralize some employees who may consider that as discrimination and hence hinder their performance leading to decreased organization performance (Sekulic, Spasic, Mirkov, Cavar \& Sattler,2013).

In the current changing environment, businesses are adopting various hiring strategies to improve the organization's overall performance. A study carried out in India by Chaudhry (2016) analyzed the role of gender and ethnicity diversity on an employee's performance in IT companies. The study used 300 respondents where 60 were selected from each company. A primary data collection method using a self-administered questionnaire was also adopted. The study findings showed a significant effect of gender diversity on employee performance in the companies. The study findings could not be generalized to other companies because the study was carried out in information technology institutions only.

A study was done by Alicia and Thomas (2016) investigating the effect of gender diversity on the quality of research in selected higher learning institutions in the United Kingdom. The study targeted 200 employees chosen using a stratified random sampling technique. Multiple panel regression was adopted, and the study findings indicated gender diversity had a negative effect on employee research quality when other factors were not under control. When the controllable variables such as faculty maturity, faculty age, and institution size were introduced, the positive impact disappeared.

Another study on workforce gender diversity and organizational performance revealed that workgroups with a balanced number of genders tend to be more productive than when one gender dominated the group (Hoogendoorn, Oosterbeek \& Van Praag, 2013). There is better performance in gender-diverse groups because conflicts are minimized. There is high learning in terms of training among different sexes, which can be done through various knowledge-sharing approaches and experiences, thus supporting each other. In management positions, gender diversity has yielded positive results. Organizations that have absorbed females in their management positions improve strategic level management standards (Sekulic, Spasic, MMirkov, Cavar \& Sattler, 2013).

An investigation done by Joecks, Pull, and Vetter (2013) on the influence of boardroom gender diversity on the performance of an organization revealed that gender balance improved the quality of decisions made in the organizations. Inclusivity of both sexes in boardrooms boosts managerial information and decision-making processes, contributing to effective strategy formulation. Nakagwa and Schreiber (2014) sought to establish the influence of women managers on firm performance. The findings revealed gender diversity in the workforce encourages innovativeness and high-quality problem solutions because of the combination of diverse views presented by both genders in the managerial teams.

Noland, Moran, and Kotschwar (2016) studied the influence of gender balance in the workplace. The findings; showed no significant difference between men and women in terms of task execution in the organization. This was different from the case decades ago when men were considered superior to women. Therefore, most employees in the organization were dominated by men. Today all gender goes to school to seek education. Even household chores and responsibilities are shared by both indiscriminately. Another case study by 
Busolo (2017) sought to look at the influence of diversity at the workplace on performance. The researcher examined gender, age, education level, and culture as the vital measurement variables. Regarding the final findings, the study established that leadership and quality of management, job satisfaction, culture, and competitiveness for both sexes lead to enhanced performance and productivity.

Organizations with gender inequality perform poorly due to a lack of motivation among employees. Employee discrimination based on gender lowers the discriminated gender's morale, motivation, and self-esteem, making them feel inferior leading to difficulties in performing their assigned tasks. In cases where there is low gender diversity is caused by unethical practices of favoring specific people for promotions, maybe with the belief that female employees cannot make better leaders and cannot achieve best results for the organization like men end up performing poorly (Nakagwa et al., 2014).

Abdullah (2014) examined the relationship between gender diversity and employee performance; a Malaysian airlines case study. The researcher targeted top and middle-level managers in the airline, where a descriptive research design was used. The findings revealed that gender diversity had a positive statistical relationship with employee performance in the airline. The study recommends that human resource management develop policies to enhance workplace diversity. Further study by Elsaid (2012) on the effect of workplace diversity and performance of the pharmaceutical industry in Egypt acknowledged a positive relationship between workplace diversity and organization performance.

Odhiambo, Gachoka, and Rambo (2018) sought to determine the relationship between gender diversity and employee performance of public universities in Western Kenya. The study targeted four public universities in Western Kenya, where the 120 heads of departments were selected as the research respondents. A mixed design method was adopted, and data was collected using the primary method. Specifically, the study adopted survey data collection method. The study findings established a positive relationship between gender diversity and employee performance. The recommendations were the number of female employees should be increased in the institutions to meet the affirmative policies of the government. More studies need to be carried out in different institutions in western Kenya to determine whether the findings of this study apply.

A study by Munjuri et al. (2013) sought to examine the effect of gender diversity in the banking industry in Kenya; it revealed that the banking industry in the country had put in strategies aimed at managing diversity. These strategies supported the idea of inclusivity and equal opportunities for all groups in an organization.

\section{Conceptual Framework}

In this study, gender diversity represented the independent variables, while the dependent variable was described by employee performance and was measured by achievement of targets, reduction of complaints, quality of service delivery, the quantity of output.

\section{Figure 1: Conceptual Framework}

\section{Independent Variable}

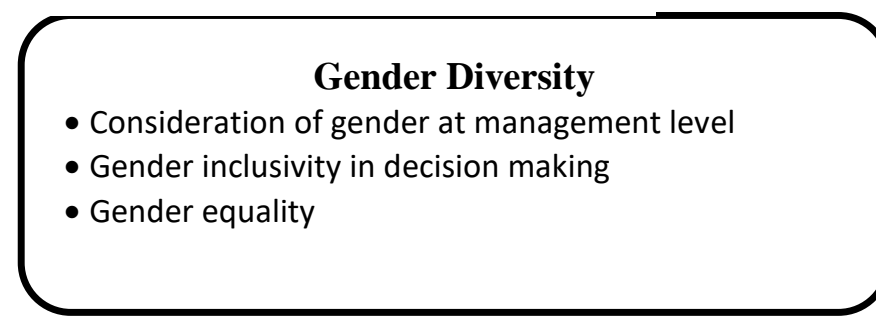

Dependent Variable

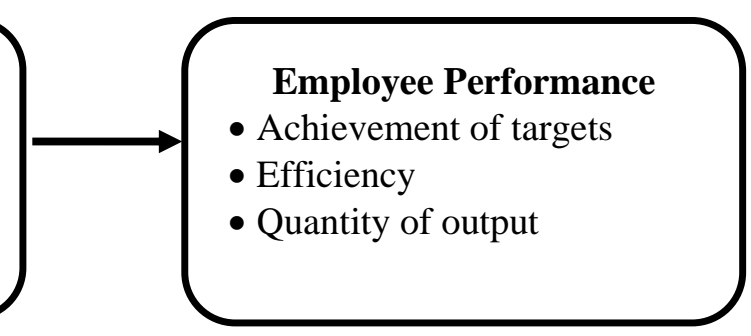




\section{METHODOLOGY}

The study used a correlational research design. The research design was considered appropriate because it gives an unbiased representation of the study population, and it can be used to examine the nature of relationships between variables (Hair, Page, \& Brunsveld, 2019). Fisher's formula was used to determine the sample size for the study, which was 91 individuals, while a stratified random sampling technique was used in selecting the study's participants. According to Jung and Sin-Ho (2014), this formula is applicable where there is a large population, but the researcher does not know the variability in the proportion used for the study.

A structured questionnaire administered individually by the researcher was used to obtain primary data for the study. This data was then coded into SPSS and analyzed using correlation and regression analysis. The study findings were presented using frequencies tables, including means and standard deviations. The reliability of the research instrument was assessed, and a Cronbach's s alpha coefficient of 0.895 was obtained, which was considered ideal for the study. The validity of the research instrument was also enhanced by carrying out a comprehensive literature review and consultation with the subject experts in human resource management. All the ethical considerations such as voluntary participation, confidentiality, and anonymity were all adhered to while collecting data.

\section{RESULTS AND DISCUSSION}

Data were analyzed using descriptive and inferential (regression and correlation) statistics.

\section{Descriptive Statistics}

The study sought to assess the relationship between gender diversity and employee performance at the county government of Bomet. Opinions were sought from the respondents and evaluated against a five-point Likert scale to assess the level at which they agreed with the provided responses. The findings were presented using tables with means and standard deviation.

Table 1: Gender Diversity and Employee Performance

\begin{tabular}{lll}
\hline Statement & Mean & Std. Dev. \\
\hline Gender balance in management positions influences employee performance. & 4.103 & 0.306 \\
\hline The county government encourages gender inclusivity in decision-making. & 4.023 & 0.549 \\
\hline $\begin{array}{l}\text { Lack of equal treatment of employees based on gender affects employee } \\
\text { performance. }\end{array}$ & 3.896 & 0.952 \\
$\begin{array}{l}\text { Gender equality in appointing management positions of the County } \\
\text { government contributes to employee performance. }\end{array}$ & 0.011 & 0.560 \\
\hline $\begin{array}{l}\text { The same treatment of male and female workers enhances employee } \\
\text { performance. }\end{array}$ & & 0.553 \\
\hline
\end{tabular}

The findings in Table 1 established that most respondents agreed that gender balance in management positions influences employee performance $(M=4.103 ; S D=0.306)$. They agreed that the county government encourages gender inclusivity in decision-making $(M=4.023 ; S D=$ 0.549 ). They also agreed that lack of equal treatment of employees based on gender affects employee performance $(M=3.896 ; S D=0.952)$. Further, they agreed that gender equality in appointing management positions of the county government contributes to employee performance $(M=4.011$; $S D=0.560)$. The same male and female workers' treatment enhances employee performance $(M=$
3.862; $S D=0.553$ ). These findings were in line with the results of Chaudhry (2016), which indicated a significant effect of gender diversity on employee performance in the companies; Abdullah (2014) the study findings revealed that gender diversity had a positive statistical relationship with employee performance in the airline. Odhiambo, Gachoka, and Rambo (2018) indicated a positive relationship between gender diversity and employee performance. 
East African Journal of Business and Economics, Volume 5, Issue 1, 2022

Article DOI: https://doi.org/10.37284/eajbe.5.1.564

Table 2: Employee Performance

\begin{tabular}{lll}
\hline Statement & Mean & Std. Dev. \\
\hline Employee diversity enhances the achievement of targets. & 3.218 & 0.945 \\
\hline Employee diversity leads to decreased complaints & 2.712 & 0.776 \\
\hline Employee diversity enhances efficiency in service delivery & 2.643 & 0.862 \\
\hline Employee diversity enhanced the quality-of-service delivery. & 2.816 & 0.869 \\
\hline Employee diversity enhances the quantity of output produced. & 3.000 & 0.849 \\
\hline
\end{tabular}

From Table 2, the respondents agreed that employee diversity enhanced the achievement of targets $(M=$ 3.218; $S D=0.945)$. Employee diversity leads to decreased complaints $(M=2.712 ; S D=0.776)$. The respondents agreed that employee diversity enhances efficiency in service delivery $(M=2.643$; $S D=0.862$ ). Employee diversity improved the quality-of-service delivery $(M=2.816 ; S D=$ 0.869). Finally, the respondents agreed that employee diversity enhances employee productivity $(M=3.000 ; S D=0.849)$.

\section{Inferential Statistics}

Table 3: Regression Model Summary
The study carried out a regression analysis to assess the cause-and-effect relationship between the dependent and independent variables, whose findings are presented in the subsequent sections.

\section{Regression Model Summary}

The regression model was used to indicate the nature of the relationship between Gender diversity and Employee Performance. The results are shown in Table 3.

\begin{tabular}{lllll}
\hline Model & R & R Square & Adjusted R Square & Std. Error of the Estimate \\
\hline 1 & $0.850^{\text {a }}$ & 0.723 & 0.701 & 0.50387 \\
\hline
\end{tabular}

a. Predictors: (Constant), Gender diversity

In the regression model summary, $\mathrm{R}$, which indicates the strength of the relationship, was found to be 0.850 . In contrast, the coefficient of determination $\left(\mathrm{R}^{2}\right)$, which measures the proportion of variance, was $0.723(72.3 \%)$. This implies that change in employee performance in the county government can be explained by $72.3 \%$ of the predictor variable, while other variables could explain $27.7 \%$ not under study.

\section{Analysis of Variance}

Analysis of variance was carried out to assess whether the regression model adopted for the study was a suitable fit for the obtained data. The results are outlined in Table 4.

Table 4: Analysis of Variance

\begin{tabular}{|c|c|c|c|c|c|c|}
\hline \multicolumn{2}{|c|}{ Model } & Sum of Squares & $\mathrm{df}$ & Mean Square & \multirow{3}{*}{$\begin{array}{l}\mathrm{F} \\
11.648\end{array}$} & \multirow{2}{*}{$\begin{array}{l}\text { Sig. } \\
0.000^{6}\end{array}$} \\
\hline 1 & Regression & 11.829 & 4 & 2.957 & & \\
\hline & Residual & 20.818 & 82 & 0.254 & & \\
\hline & Total & 32.647 & 86 & & & \\
\hline
\end{tabular}

a. Dependent Variable: Employee Performance

b. Predictors: (Constant), Gender diversity

The findings in Table 4 established a statistical relationship between workforce diversity and employee performance. Thus $\mathrm{F}(1,82)=2.957$, $\mathrm{P}<0.05$. The findings imply that the obtained data was a good fit for the obtained data. Gender diversity had a positive and significant relationship with employee performance at Bomet County.

96 | This work is licensed under a Creative Commons Attribution 4.0 International License. 
East African Journal of Business and Economics, Volume 5, Issue 1, 2022

Article DOI: https://doi.org/10.37284/eajbe.5.1.564

Table 5: Regression Analysis

\begin{tabular}{|c|c|c|c|c|c|c|}
\hline \multirow{2}{*}{\multicolumn{2}{|c|}{ Model }} & \multicolumn{2}{|c|}{ Unstandardized Coefficients } & Standardized & \multirow[t]{2}{*}{$\mathrm{t}$} & \multirow[t]{2}{*}{ Sig. } \\
\hline & & $\mathbf{B}$ & Std. Error & Beta & & \\
\hline & (Constant) & 6.494 & 1.100 & & 5.904 & 0.000 \\
\hline & Gender Diversity & 0.421 & 0.157 & 0.419 & 2.688 & 0.000 \\
\hline
\end{tabular}

a. Dependent Variable: Employee Performance

The findings in Table 5 indicated that gender diversity positively correlates with employee performance in the county government of Bomet $(\mathrm{P}<0.05)$. According to these findings, the influence of gender diversity on employee performance is statistically significant at $5 \%$ of significance $(t=$ $2.688, \mathrm{P}<0.05)$. The results revealed that a unit increase in gender diversity would contribute to a $0.421 \quad(\beta=0.421)$ increase in employee performance in the county government of Bomet.

\section{CONCLUSION AND RECOMMENDATION}

The study concluded that there was a significant relationship between gender diversity and employee performance in the county government of Bomet. It was, therefore, clear that the county government embraced gender diversity which led to enhanced employee performance. Thus, the study recommended that the county governments adopt gender balance in management positions and gender inclusivity in decision making. The county governments must also treat employees equally despite their gender, which enhances equality in the county; thus, this will influence employees' performance. Gender balance should also be considered when the county government appoints employees to senior management positions. This will make all the employees feel like they have equal chances to be appointed to managerial positions, which will motivate them, leading to improved performance.

\section{REFERENCES}

Abdullah, S. N. (2014). The causes of gender diversity in Malaysian large firms. Journal of Management \& Governance, 18(4), 1137-1159.

Anjiri, V. (2018). Effect of Workforce Diversity On Performance of Information Technology Firms in Nairobi County (Doctoral dissertation, KCA University).

Busolo, E. (2017). The Impact of Workforce Diversity on Organizational Performance: A Case Study of Aar Group (Doctoral dissertation, United States International University-Africa).

Chaudhry, S. (2016). Role of gender and ethnicity diversity on the performance of employee. International Journal of Research in IT and Management, 6(11), 112-119.

Elsaid, A. M. (2012). The effects of cross-cultural work force diversity on employee performance in Egyptian pharmaceutical organizations. Business and Management Research, 1(4), 162175

Eshetu, S. (2017). The Effect of Workforce Diversity on Employee Performance (The Case of Addis Credit and Saving Institution SC) (Doctoral dissertation, Addis Ababa University)

Farooqi, O. (2017). Managing Age Diversity in Workplace-Bridging The Gap Between the Young and The Aging for Effective Workforce Management.

Gacheri, M. (2012). Workforce diversity management and employee performance. $D B A$ Africa Management Review, 3(1), 1-21.

Hair Jr, J. F., Page, M., \& Brunsveld, N. (2019). Essentials of business research methods. Routledge.

Hogg, M. A., Terry, D. J., \& White, K. M. (1995). A tale of two theories: A critical comparison of identity theory with social identity theory. Social psychology quarterly, 255-269. 
Hoogendoorn, S., Oosterbeek, H., \& Van Praag, M. (2013). The impact of gender diversity on the performance of business teams: Evidence from a field experiment. Management Science, 59(7), 1514-1528.

Iqbal, H., \& Shah, F. (2015). Impact of workforce diversity on organizational performance in the education sector of Karachi Pakistan. International Journal of Scientific and Engineering Research, 6(10), 1258-1273.

Joecks, J., Pull, K., \& Vetter, K. (2013). Gender diversity in the boardroom and firm performance: What exactly constitutes a "critical mass?". Journal of business ethics, 118(1), 6172.

Jung, Sin-Ho. (2014). Stratified Fisher's Exact Test and its Sample Size Calculation. Biometrical journal. Biometrische Zeitschrift. 56. 129-40.

Kulik, C. T. (2014). Working below and above the line: The research-practice gap in diversity management. Human Resource Management Journal, 24(2), 129-144.

Kunze, F., Boehm, S., \& Bruch, H. (2013). Organizational and employee workforce performance consequences of age diversity: Inspecting the role of diversity-friendly HR policies and top managers' negative age stereotypes. Journal of Management Studies, 50(3), 413-442.

Kurtulus, F. A., \&Tomaskovic-Devey, D. (2012). Do female top managers help women to advance? A panel study using EEO-1 records. The ANNALS of the American Academy of Political and Social Science, 639(1), 173-197.

McDowell, C., \&Fossey, E. (2015). Workplace accommodations for people with mental illness: A scoping review. Journal of occupational rehabilitation, 25(1), 197-206.

Munjuri, M. G., \& Maina, R. M. (2013). Workforce diversity management and employee performance in the banking sector in Kenya. DBA Africa management review, 3(1).

Mwinami, S. J. (2014). An assessment of the effect of workforce Diversity on employee performance at Tanesco (Doctoral dissertation, Mzumbe University).

Nakagawa, Y., \& Schreiber, G. M. (2014). Women as drivers of Japanese firms' success: The effect of women managers and gender diversity on firm performance. Journal of Diversity Management (JDM), 9(1), 19-40.

Odhiambo, M. W., Gachoka, H. G., \& Rambo, C. M. (2018). Relationship between Age Diversity and Employee Performance of Public Universities in Western Kenya.

Patten, E. (2016). Racial, gender wage gaps persist in United State despite some progress. U.S.: Pew Research Center.

Preeti, B., Poonam, L., \& Ekanshi, G. (2014). Workforce diversity management: Biggest challenge or opportunity for 21st century organizations. IOSR Journal of Business and Management, 16(4), 102-107.

Sabharwal, M. (2014). Is diversity management sufficient? Organizational inclusion to further performance. Public Personnel Management, 43(2), 197-217.

Sekulic, D., Spasic, M., \&Esco, M. R. (2014). Predicting agility performance with other performance variables in pubescent boys: a multiple-regression approach. Perceptual and motor skills, 118(2), 447-461.

Wilden, R., Gudergan, S. P., Nielsen, B. B., \& Lings, I. (2013). Dynamic capabilities and performance: strategy, structure and environment. Long Range Planning, 46(1-2), 72-96.

98 This work is licensed under a Creative Commons Attribution 4.0 International License. 